\title{
Microtelcos in Latin America and the Caribbean
}

\author{
Hernan Galperin \\ UNIVERSIDAD DE SAN ANDRÉS/USC \\ Bruce Girard ${ }^{1}$ \\ COMUNICA
}

\begin{abstract}
The problem discussed in this paper is the failure of ICT networks and services to effectively reach the poor, particularly those living in rural areas, in Latin America and the Caribbean. The conventional answer to this problem has been to create incentives and offer public subsidies for traditional operators to cover the difference between tariffs and cost-recovery levels. This paper examines a different answer. We suggest that microtelcos - small-scale telecom operators that combine local entrepreneurship, municipal efforts, and community action - can play an important role in extending ICT services in the region, particularly in areas unattractive to large private operators. In fact, we show that a variety of microtelcos are effectively servicing many of these areas, despite a less than favorable regulatory environment and little access to public subsidies. The paper examines the theoretical case for microtelcos as an effective alternative to address the ICT needs of the poor, presents examples of microtelcos drawn from across the region, and suggests how existing regulatory obstacles for microtelcos may be removed.
\end{abstract}

\footnotetext{
${ }^{1}$ Research support was provided by Sylvia Cadena and Diego Pando. We would like to thank Francisco Proenza, François Bar and Miguel Saravia, along with our colleagues from REDIS-DIRSI, for comments on earlier drafts.
} 
It is no longer adequate to view the provision of information and communication technology (ICT) services as a dichotomy between public utilities and large private operators. In both developed and developing nations, a diversity of organizations (among them cooperatives, municipal governments, universities and local entrepreneurs) participate in the deployment and operation of ICT networks. This is most noticeable in markets unattractive to traditional operators, where a variety of local arrangements exist to service high-cost or low-income communities. These arrangements are often hybrids of small-scale entrepreneurship, municipal efforts, and community action. What distinguishes them from traditional operators is the local scale, the use of low-cost technologies and innovative business models, and the strong community links. We refer to them as microtelcos.

The problem discussed in this paper is the failure of ICT networks and services to effectively reach the poor, particularly those living in rural areas, in Latin America and the Caribbean. After over a decade of market-driven reforms in the telecommunications sector, it has become clear that large private operators are no more likely to serve economically unattractive areas with sparse populations or low incomes than the public operators of the past. In many countries in the region, the gap between urban and rural ICT infrastructure has increased since the onset of reforms. ${ }^{2}$ Where networks do reach - particularly in the case of mobile telephony coverage does not mean access since the rural poor are often unable to afford services engineered for wealthier urban customers.

The conventional answer to this problem has been to create incentives for traditional operators to service unattractive areas and offer public subsidies to cover the difference between tariffs and cost-recovery levels. While these policies have a respectable record in the developed world, the experience in Latin America is at best mixed (Estache, Manacorda, and Valletti, 2002). Efficient administration of universal service programs has proven a difficult task for the newly created industry regulators, many of which lack adequate resources (Wallsten and Clarke, 2002). Even when these programs are successful, the level of funding limits large-scale replications. It is widely acknowledged that the resources needed to address existing ICT infrastructure needs far outstrip available public subsidies in the region.

This paper examines a different answer to this problem. We suggest that microtelcos can play an important role in extending ICT coverage in the region, particularly to high-cost or low-income areas unattractive to large private operators. In fact, we show that a variety of microtelcos are already servicing many of these areas, despite a less than favorable regulatory environment and little access to public subsidies. Their advantage lies in the mobilization of local resources, such as in-kind

${ }^{2}$ See Galperin (2005). 
labor and private rights of way, as well as in the use of new low-cost technologies and innovative business models. Furthermore, much like their close cousins in water, electricity, and sanitation, microtelcos have a development impact that goes beyond the provision of services, for local ownership and management has been consistently found to spur entrepreneurship and nurture social capital (Dongier et al., 2003).

The paper is organized as follows. In the first section we discuss the theoretical case for microtelcos as an effective alternative to address the ICT needs of the poor. Drawing from the work of Ostrom (1996) and others, we argue that there is a large scope for co-production in the delivery of ICT services between municipal government, community-based organizations (CBOs), and the private sector. Next we discuss how technological innovations are significantly enlarging the scope of action for microtelcos. We then introduce a taxonomy of microtelcos and present examples drawn from across the region. Based on the results of a regional survey of the rules governing deployment of low-cost solutions for local access networks, we argue that an enabling regulatory framework for microtelcos is lacking. We conclude with recommendations for creating such a framework.

\section{The Co-production of ICT Services}

Public services can be delivered in a variety of ways. For many decades, most countries relied on large state-owned utilities to provide basic infrastructure services such as electricity, water and telecommunications. A major paradigm shift took place during the last decades of the $20^{\text {th }}$ century, paving the way for the privatization of many public utilities and far-reaching regulatory reforms aimed at open markets to competition. The shift was particularly marked in the telecommunications industry, where rapid technological innovation also contributed significantly to undermine monopoly regimes. ${ }^{3}$ It is without a question that these changes unleashed an unparalleled wave of innovation and investment in the ICT industries, first in the developed world and later in developing economies. However, after two decades of reforms the limitations of the new paradigm are now becoming clear.

It is widely recognized that large private operators are no more likely to serve high-cost or low-income customers than were state-owned utilities. This should not be surprising. Ultimately, whether in public or private hands, large utilities face similar challenges in servicing these areas: low or fluctuating incomes, low (and often decreasing) population density, lack of reliable information about customers and their demand preferences (including willingness-to-pay), lack of credit assessment mechanisms (including a formal addressing system), and lack of complementary

\footnotetext{
${ }^{3}$ There is a vast literature that documents these changes. For an overview see Noll (2000).
} 
infrastructure (such as electricity and roads), among others. Other factors further discourage large private operators from tailoring service to the poor. The shared costs structure of telecom networks means that providing more and better services to the more profitable customers increases the cost of provision to all - even to those requiring less quality at more affordable prices. In many cases, rigid regulations on tariffs and engineering standards further discourage price/quality differentiation. Lastly, the availability of cost-based public subsidies sometimes deters large operators from seeking more efficient alternatives to serve the poor. ${ }^{4}$

Therefore while large private utilities are well suited for building network backbones and retailing services in wealthy urban areas, their organizational advantages tend to diminish as we approach the last-mile segment in high-cost or low-income communities. Large utilities lack either the flexibility or the incentives to seek alternative combinations of inputs better suited to serve poor customers. Microtelcos, by contrast, thrive on creative entrepreneurship. Because their core business is to serve customers unattractive to large operators, they actively seek combinations of capital, labor and technology that maximize returns based on their knowledge of local conditions and demand preferences. This involves deploying low-cost technologies, bundling ICT with related services (such as training, financial, and legal services), taking advantage of related infrastructure (such as roads and water systems), and finding business models (including payment collection mechanisms) appropriate to local conditions.

A key factor is that not all inputs necessary to optimize last-mile service delivery to the poor can be mobilized efficiently by large private utilities. Labor for infrastructure building and maintenance can often be contributed by customers themselves, often at little opportunity costs given high levels of underemployment in many poor regions. There are abundant examples of community members volunteering to set up towers, string cables, and construct facilities necessary for community network projects. It is also the case that while potential customers in these areas typically lack financial resources, they often control critical rights of way for wiring and antenna siting. Condominial lines running through household yards (and thus owned and maintained by customers themselves) have long served to extend urban sanitation networks in Brazil and Bolivia (Watson, 1995; Foster and Irusta, 2003). This is also how much of rural America was wired for telephony in the early $20^{\text {th }}$ century (Fischer, 1992). Today, low-cost wireless technologies are renewing opportunities for end-user deployment and control of the first segment of the network.

${ }^{4}$ This is not the case however with smart subsidies which are increasingly used by telecom funds in Latin America and elsewhere (see Wellenius, 2001). 
Municipal governments are another important actor in the provision of ICT services in these areas. In Latin America, democratic changes since the 1980s have been accompanied by decentralization programs aimed at increasing local government autonomy, creating an enabling institutional setting for the delivery of public services at the municipal level. As the examples discussed below reveal the role played by local governments in microtelco projects in Latin America varies widely (as it does elsewhere). In many cases, provincial authorities have been instrumental in aggregating demand, developing e-government applications, facilitating planning, and providing training to potential users. In other cases, municipalities have cofinanced infrastructure investments through a variety of partnerships with private operators. Yet in others local authorities have engaged in the building and operation of a non-competitive network segment (e.g., a fiber backbone) on a wholesale basis.

Different organizations thus have a comparative advantage in each of the tasks involved in the provision of ICT services to the poor. The concept of co-production captures this well. Co-production refers to the potential complementarities that exist between different organizations in the delivery of a service (Ostrom, 1996; Gerrard, 2000). Figure 1 illustrates this potential in the delivery of broadband services. Large private operators are well positioned to build backhaul and switching facilities, though they are often reluctant to bear the risks of extending services into thin markets. Local entrepreneurs or cooperatives, by contrast, can effectively aggregate local demand, mobilize resources, develop appropriate applications, and

Figure 1: The Co-production of Broadband Services

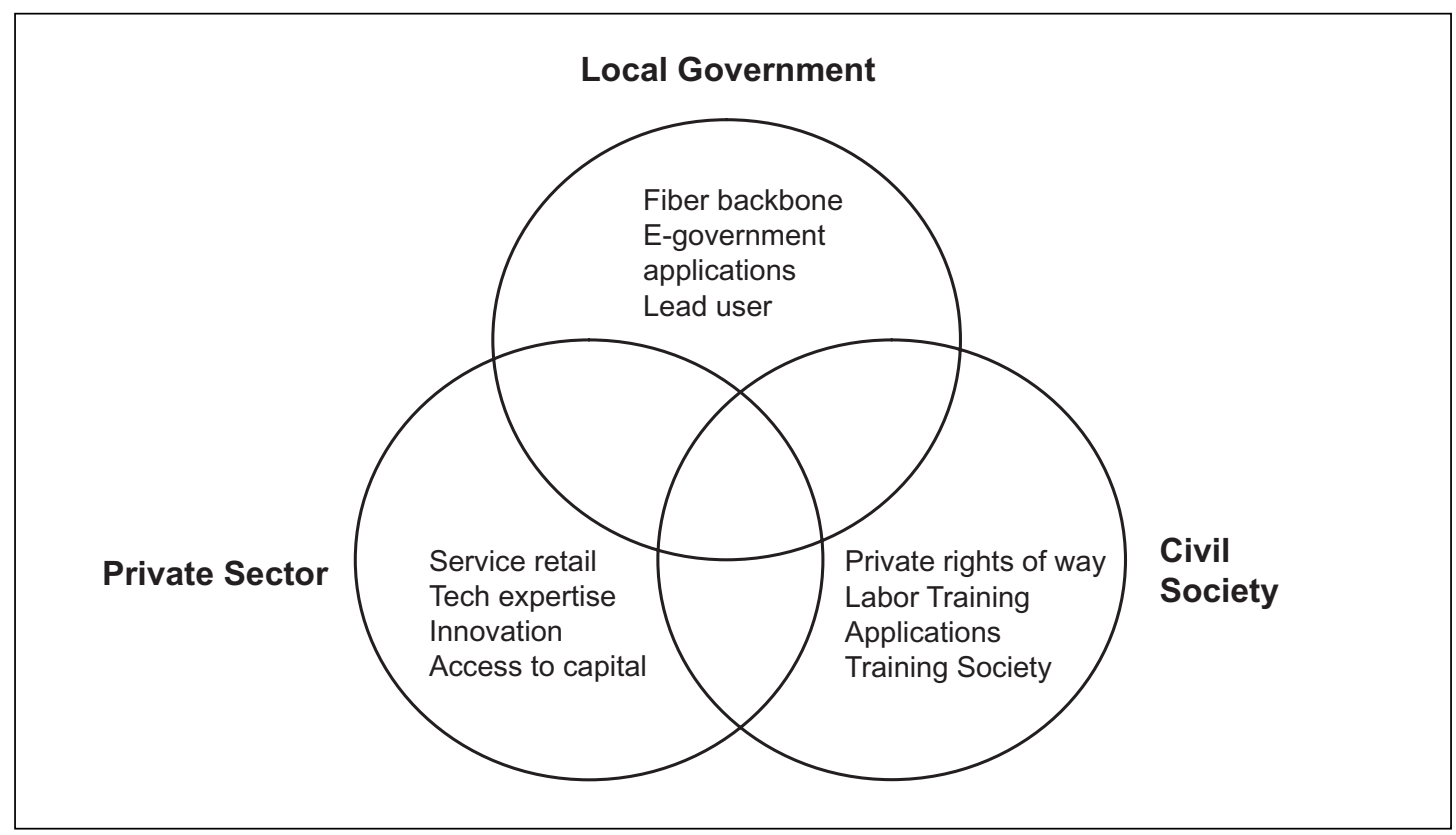


experiment with input combinations that better suit local needs. This often requires active support from local authorities to facilitate coordination, stimulate demand, and operate essential facilities.

Microtelcos are well positioned to take advantage of co-production strategies because in each case the optimal combination of inputs contributed by local government, civil society, and the private sector will vary according to local conditions. For example, condominial systems and service cooperatives are better suited in cases where strong CBOs are already present (as in the case of the Chancay-Huaral project discussed below). Municipal network projects offer an alternative when strong local institutions exist (as in the Piraí case discussed below), when fiscal revenues are decentralized, or when the municipality is already involved in the delivery of other public services. Local entrepreneurship and capital may be activated when an enabling regulatory environment is present, and when complementary services (backhaul lines and e-government application for example) are available. The most effective co-production arrangement for the provision of ICT services to the poor will thus depend on the institutional attributes of each community.

\section{The Enabling Role of New Technologies}

Laying telecom wires is not unlike paving roads. It requires large upfront investments, economies of scale are pervasive, and the architecture of the network has to be carefully planned in advance because resources are not easily redeployed. The process involves making many ex ante assumptions about how services will be used, by whom, and at what price. As a result, ICT networks were typically built by large operators (mostly public in the past, mostly private today) who were positioned able to assemble the financing and manage the risks involved in network development. Recent innovations in wireless communication and service applications are nonetheless challenging these premises. These innovations are significantly reducing the minimum efficient scale of telecom providers, allowing a variety of new actors, from small entrepreneurs to municipalities to user cooperatives, to enter the market.

A leading example is the combination of new wireless local area networking (WLAN) technologies such as Wi-Fi with wireless backbone solutions such as VSAT or the emerging WiMax standard for the provision of Internet access in remote areas. ${ }^{5}$ Low-cost WLAN systems have been deployed by small entrepreneurs and cooperatives to service rural communities in South Asia and Latin America at a cost several orders of magnitude below that of comparable wired solutions (Best, 2003;

${ }^{5}$ For a detailed discussion of these technologies see chapter 6. 
Galperin, 2005). Many small and mid-sized cities are taking advantage of these innovations to extend Internet access from a few broadband connections in government buildings to the entire community, thus lowering per user costs. Local entrepreneurs are tinkering with the technology to build point-to-point links over several kilometers to connect communities that lack adequate wired backhaul infrastructure (or to bypass links controlled by incumbents). ${ }^{6}$

The much flatter cost curve of WLAN technologies undermines the comparative advantages of large operators in the deployment of local networks for broadband Internet access. While upfront costs are reduced, WLAN networks are also more easily scalable or redeployed, allowing microtelcos to make modest initial investments and scale up later following demand. Instead of poles and wires, WLAN technologies take advantage of a natural resource underutilized in many poor areas: the radio spectrum. Therefore market entry is less defined by firm size than by spectrum allocation policies. Small wireless ISPs (WISPs) have flourished in countries where governments have opened frequency bands for unlicensed use, particularly in areas underserved by traditional operators. ${ }^{7}$

Furthermore, new mesh networking protocols are enabling the growth of condominium-style networks. This emerging architecture is based on end-users both receiving and relaying data from peer users, resulting in a network that can span a large area with only a few broadband links. This type of architecture is well suited to cases where backhaul links are scarce (and expensive), as is the case in many poor areas, as well as where spectrum is congested, since each network node need only transmit as far as the next node (which also minimizes power requirements, another concern in many poor areas). Another advantage is robustness: when each enduser is connected to several others, multiple data routes may be available, thus bypassing failed nodes. And as more nodes are added, total network capacity grows (Benkler, 2002). While the technology is still emerging, pilot projects are already operational in Africa and elsewhere. ${ }^{8}$

\footnotetext{
${ }^{6}$ There are also number of last-mile wireless alternatives, and the selection of the technology will often depend on factors such as geography, population density and services required. One promising technology used by microtelcos in Brazil and Argentina is corDECT. Developed at the Indian Institute of Technology, corDECT is a wireless local loop (WLL) technology designed to provide cost-effective, simultaneous high-quality PSTN compatible voice and high speed data connectivity for rural areas. With corDECT, rural connectivity costs are reduced from $\mathrm{U} \$ 1,500$ to about $\mathrm{U} \$ 300$ per line (Jhunjhunwala, 2000). The corDECT system is also highly modular - a single switch system can economically scale from 100 to 5,000 subscribers.

${ }^{7}$ In the U.S., which first allowed unlicensed operation of radio devices and today provides over $550 \mathrm{MHz}$ of spectrum on a license-exempt basis, there are an estimated 6,000 mom-and-pop WISPs servicing rural and other areas underserved by traditional broadband operators (FCC Wireless Broadband Access Task Force, 2005).
}

${ }^{8}$ See www.meraka.org.za for pilots in rural Africa. 
New low-cost applications are having similar effects at the services layer. A leading example is Voice over IP (VoIP), which refers to a family of technologies that allow packetization and routing of voice communication over an Internet Protocol (IP) network instead of a traditional circuit-switched network. There are many advantages to IP telephony, including lower costs and more efficient use of facilities, and many large operators are migrating calls from conventional PSTN to IP networks. But the technology is particularly relevant to microtelcos because it enables provision of telephony at a fraction of the investment needed to build and maintain a traditional telephone network (Graham and Ure, 2005). Another advantage is that IP telephony is largely based on nonproprietary standards, and much of the equipment is available off-the-shelf for adaptation to local conditions.

A number of technological innovations are thus eroding the economic advantages hitherto enjoyed by large telecom operators, enabling microtelcos to extend ICT services further out into areas unattractive to conventional operators. These technologies share a number of advantages, among them lower costs, modularity based on open standards, less regulatory overhead, simple configuration and maintenance, scalability, and support for multiple applications. However, whether microtelcos and other new entrants are able to take advantage of these innovations depends to a large extent on the existence of technologically-neutral market rules, which as we shall see below is not always the case in Latin America and the Caribbean.

\section{Microtelcos in Latin America: Case Studies}

Critics often contend that arrangements other than large private utilities are inefficient and provide suboptimal public services (high tariffs, low quality) to the poor. In the next section we provide ample evidence to the contrary. Our findings, based on case studies from across the region that reflect different organizational arrangements, indicate that a variety of microtelcos are effectively servicing areas of little interest to traditional operators, providing affordable services and more generally acting as a catalyst for sustainable development in the communities they serve.

\subsection{TELEPHONE COOPERATIVES IN ARGENTINA}

A long-established model for microtelcos in Latin America and elsewhere is the telephone cooperative. This model is found for the most part in rural areas, where telephone cooperatives first emerged as the offspring of agricultural cooperatives established for various other purposes..$^{9}$ In Argentina, telephone cooperatives emerged in

\footnotetext{
${ }^{9}$ The notable exception is Bolivia, where cooperatives also service the major urban areas. The case is nonetheless atypical, for Bolivia's telephone cooperatives are not the product of organized efforts by users but were rather created by the government in 1985 to replace the incumbent municipal telephone companies (Calzada and Dávalos, 2005).
} 
the early 1960s from efforts by local residents in areas poorly served by the former state-owned operator ENTEL. While not supported by the government, cooperatives were tolerated by ENTEL since they operated in areas considered unprofitable and brought modest revenues through tariff-sharing agreements. ${ }^{10}$ By 1965 , over 100 telephone cooperatives were operating across the Argentine territory.

When reforms began in the telecom sector in 1990, there were over 300 telephone cooperatives, many of which part of multi-service utilities that provided electricity and water services as well. With the privatization of ENTEL, telephone cooperatives faced a period of uncertainty until 1992, when the government granted existing cooperatives a local telephony license on similar terms to those granted to the new private incumbents (which included a seven-year exclusivity period). In 1999, faced with the imminent expiration of the exclusivity period, telephone cooperatives joined forces to enter the long-distance and public telephony markets through the creation of a private subsidiary (TECOOP). By 2004, TECOOP operated approximately 230 public telephones, most of them located in remote areas.

Evaluating the performance of Argentine telephony cooperatives is difficult because of the sheer diversity of cases. Two-thirds of the cooperatives operate in small communities with less than 10,000 inhabitants, and the majority of them (57\%) service less than 500 subscribers (although there are a handful of "large" cooperatives with over 5,000 subscribers). Overall, our findings indicate that telephone cooperatives have played a key role in extending basic as well as advanced ICT services outside the main urban areas. With over 600,000 subscribers, cooperatives account for about $8 \%$ of the Argentine fixed telephony market. In many of the poorest and more isolated provinces, however, their market share is much higher. In the Province of Jujuy for example, cooperative lines represent $53 \%$ of total installed lines, while in Formosa they account for $46 \%$.

Standard measures reveal that in most cases telephone cooperatives compare favorably with traditional operators despite serving the less desirable markets. As Table 1 shows, average teledensity in the markets served by cooperatives is only moderately lower than in areas served by traditional operators (which include all major urban centers). This is remarkable if one considers that, on average (and regardless of income), a rural household in Latin America is ten times less likely than an urban one to have a telephone line. ${ }^{11}$ In fact, if one disregards the Buenos Aires market (where the gap is higher because of the relatively high teledensity

\footnotetext{
${ }^{10}$ For much of the monopoly era (until 1990) the revenue-sharing agreement for long-distance calls between ENTEL and the cooperatives worked as follows: $60 \%$ corresponded to ENTEL, while the remaining $40 \%$ corresponded to the local cooperative.
}

${ }^{11}$ Wallsten and Clarke (2002). 
Table 1: Teledensity in Cooperative Territories vs. Total Teledensity, 1998

\begin{tabular}{|c|c|c|c|c|c|}
\hline Province & $\begin{array}{l}\text { Population in } \\
\text { cooperative }\end{array}$ & $\begin{array}{c}\text { Cooperative } \\
\text { subscribers } \\
\text { territories }\end{array}$ & $\begin{array}{l}\text { Teledensity } \\
\text { (A) }\end{array}$ & $\begin{array}{l}\text { Total Province } \\
\text { Teledensity (B) }\end{array}$ & (B-A) \\
\hline Buenos Aires & 686,736 & 109,568 & 16.0 & 22.0 & -6.0 \\
\hline Catamarca & 36,939 & 2,399 & 6.5 & 9.1 & -2.6 \\
\hline Chaco & 25,000 & 1,658 & 6.7 & 7.2 & -0.5 \\
\hline Chubut & 9,700 & 1,679 & 17.3 & 19.8 & -2.5 \\
\hline Córdoba & 183,950 & 27,837 & 15.1 & 18.4 & -3.3 \\
\hline Formosa & 82,000 & 8,472 & 10.3 & 4.5 & 5.8 \\
\hline Jujuy & 146,000 & 11,285 & 7.7 & 6.3 & 1.4 \\
\hline La Pampa & 7,265 & 1,493 & 20.6 & 19.4 & 1.2 \\
\hline Neuquén & 128,000 & 18,884 & 14.8 & 13.4 & 1.4 \\
\hline Río Negro & 25,200 & 2,547 & 10.1 & 15.9 & -5.8 \\
\hline San Luis & 39,980 & 5,251 & 13.1 & 13.5 & -0.4 \\
\hline Santa Cruz & 59,100 & 8,966 & 15.2 & 14.2 & 1.0 \\
\hline Santa Fe & 268,054 & 41,813 & 15.6 & 18.9 & -3.3 \\
\hline Total & $1,698.284$ & 241,852 & 14.2 & 19.2 & -5.0 \\
\hline Total w/o Buenos Aires & $1,011,548$ & 132,284 & 13.1 & 15.5 & -2.4 \\
\hline
\end{tabular}

Source: Secretaría de Comunicaciones (SECOM).

around the capital city), the difference in teledensity between the areas served by the incumbents and the areas served by the cooperatives is relatively small.

Our case studies also reveal that average prices for services provided by cooperatives tend to be similar or lower than those of large operators. In fixed telephony services, average connection costs are $32 \%$ lower for cooperatives. Prices for dial-up Internet access services are comparable with those of larger operators, despite higher provision costs due to lack of competitive leased lines in rural areas (nonetheless prices for xDSL services were found to be significantly higher). Part of the cost advantage is explained by faster technological adoption. Motivated by the need to service customers in low-density areas at the lowest possible cost, cooperatives are constantly seeking for lower-cost technologies appropriate for their business models. Telpin, a cooperative in a relatively wealthy community south of Buenos Aires, installed the first digital exchange in Argentina in the early 1980s, which enabled provision of a host of value-added services which the incumbent only offered after privatization (Finquelievich and Kisilevsky, 2005). 
Cooperatives have also pioneered wireless last-mile and backhaul solutions. Local loop systems based on corDECT have been deployed by cooperatives in the provinces of Chubut, Neuquen, and Cordoba, allowing fast network roll-out at a fraction of the cost of traditional copper. Wi-Fi has been the technology of choice for many cooperatives providing broadband Internet access services. Cooperatives have also been eager to enter the wireless telephony market, since competition from wireless carriers has significantly affected revenue growth. The main effort is centered around the acquisition of a national wireless license through Comarcoop, a joint venture formed by several telephony and electricity cooperatives. There are also more localized efforts such as that of CoTeCal, a telephone cooperative in the remote Patagonia city of El Calafate, which has partnered with Chinese electronics giant Huawei and the provincial government to test CDMA450, a third-generation cellular telephony system better suited to service scarcely-populated areas than traditional PCS systems. ${ }^{12}$

It is also important to acknowledge the spillover benefits to the community as a whole associated with the telephone cooperative model. Our findings indicate that cooperatives have a significant involvement in ICT training and dissemination activities (which also serve to boost demand for value-added services), while many cooperatives have also engaged in local content development (typically community portals) in association with various CBOs and local governments. Despite the lack of subsidy payments from the government, many cooperatives set special tariffs for lowincome residents while others provide free services (particularly Internet access) to public schools and libraries. Finally, telephone cooperatives promote local capacity building and nurture community solidarity, two important ingredients long identified by development scholars as critical for empowering the poor (Birchall, 2003).

\subsection{WIRELESS COMMUNITY NETWORKS IN PERU}

Recently, a number of microtelcos have emerged from existing CBOs created for purposes other than the provision of ICT services. A project in the Chancay-Huaral valley of Peru illustrates this deployment and ownership model. The ChancayHuaral river irrigates a large area of small-scale farming (95\% of farms have less than 10 hectares of land) on the sides of the valley. While the area has potential wealth due to its good land, abundant water and proximity to the markets of Lima and the north of the country, farmers have not been able to adapt their production to the fluctuations of the agricultural markets. Additionally the inhabitants of the valley have little or no access to public services and the communications infrastructure available to them is at best precarious.

\footnotetext{
${ }^{12}$ CDMA450 works on a lower frequency band (450MHz), and thus requires considerable fewer towers to cover an extensive area.
} 
CEPES, a Peruvian NGO, reasoned that there was a connection between the lack of communication and services and the fact that farmers tended to grow the same crops regardless of market prices. They also noted that the lack of communications created problems for the efficient management of the waters of the river Huaral, a common resource used by the valley's farmers and managed by the Water Users Board, a cooperative organization of the seventeen Irrigation Commissions spread throughout the valley (which are in turn composed by farmers themselves, about 6,000 in total). To address these problems, CEPES proposed to establish an agricultural information and communication system for the valley, providing farmers with training and access to information that would enable them to make better decisions, and facilitating communication among the irrigation commissions to improve water management. Because the available communications infrastructure was inadequate, a Wi-Fi network was deployed joining twelve villages in the valley and connecting them to the internet through a shared $512 \mathrm{Kbps}$ line and a VSAT link.

The desertification of Peru's coastal areas is a serious problem, and thus the local Irrigation Commission, which manages irrigation and other uses of water, is one of the most important CBOs for communities along the Chancay-Huaral valley. While the project was initiated by CEPES and funded by Peru's telecom development fund (FITEL), the Chancay-Huaral Water Users Board was selected as the owner/operator of the network because of its experience in managing infrastructure, its close contact with local farmers, and the presence of the Irrigation Commissions in each of the valley's villages. Beyond infrastructure deployment, the project emphasized the development and maintenance of a database of agricultural information, the training of farmers in the effective use of agricultural information, and the strengthening of local capacity for obtaining, distributing and using agricultural information.

As the project became operational, it also evolved to better meet local demand for ICT services. IP telephony quickly took on a central importance, not only for linking the local Irrigation Commissions and the Board but also for general use by local residents. Providing access to other local residents (beyond farmers themselves) also became a priority. Since available bandwidth far exceeds the needs of the Irrigation Commissions, a number of local institutions such as schools were invited to join the network. The Board is currently working to extend connectivity for other CBOs, public offices, and private entities, as well as to set up telecenters for the public at large.

While not immediately replicable, the Chancay-Huaral project illustrates a number of the advantages of the CBO-driven microtelco model. The adoption of IP 
telephony and the scaling of the network reveals the ability to rapidly adapt to community needs. While the decision to provide connectivity to other institutions and individuals stems in part from an interest to contribute to community development, it is also part of a sustainability plan based on cost-sharing by public, private, and civil society partners. Inter-local cooperation has also been critical, for each village is responsible for local network maintenance, with training provided by CEPES. In addition, newWLAN technologies have allowed flexibility in terms of service provision and scaling of the network with a modest initial investment. ${ }^{13}$

\subsection{MUNICIPAL NETWORKS IN BRAZIL AND ARGENTINA}

Municipal network projects have attracted much publicity (both good and bad) as of late. ${ }^{14}$ Many question local government involvement in the provision of ICT services as the new face of the old state-utility model, noting its poor record of service quality, innovation, and network extension. Yet a closer look reveals significant differences. To begin with, the new breed of projects is led by local rather than national authorities. Under the right circumstances, the delivery of public services has been recognized to be more effectively organized at the local level (Azfar and Cadwell, 2003). Municipal network projects often start from this principle, delivering services tailored to local needs and integrating ICT with broader economic and social development activities.

This is the case of Piraí, a rural municipality of about 25,000 inhabitants in the State of Rio de Janeiro, Brazil. The Digital Piraí project was started in the late 1990s when the municipality received a small grant from the Federal Government to modernize its local tax office. At the time, the entire local government ran on two phone lines and two computers. While part of these resources were earmarked for a hybrid fixed-wireless IP network to connect different government offices, local authorities realized that broadband connectivity could be extended to a much larger area at little extra cost. A community committee was then formed, which included municipal authorities and representatives from CBOs and the private sector, to chart a more ambitious plan that would extend wireless connectivity to much of the Piraí territory. The project was conceived as the cornerstone of a broader plan to diversify the local economy and attract new investments following privatization

\footnotetext{
${ }^{13}$ The initial investment reached $U \$ 33,600$, or about $U \$ 2,800$ per village.

${ }^{14}$ It is important to distinguish municipal networks from municipal e-government initiatives. Broadly speaking, municipal e-government concerns the provision of local government services over an existing network platform provided by third parties, as well as the use of ICT to improve internal government operations. By contrast, our attention is on municipal network projects where the local government is involved - in a variety of different ways - in infrastructure roll-out and the delivery of ICT services to the public.
} 
(with significant layoffs) of the state-owned power utility, then the largest local employer.

The community committee proved critical in securing partnerships with universities, NGOs, and private firms, which contributed to the project with equipment, application development, and expertise in the deployment and operation of the municipal network. The project focused on four areas: e-government the original remit of the initiative), education (including distance education in partnership with a consortium of public universities), public access points (including training in partnership with various NGOs) and SME adoption. To date, the network has over 50 broadband nodes, connecting all local government offices and most of the public schools and libraries. There is also a growing number of public access points, and a private company with majority municipal ownership has been formed to commercialize services to households and businesses.

The lessons from the Piraí case point to several success factors. First, the lack of public subsidies (beyond the small grant to modernize the tax office) forced community leaders to draw in resources through cooperation with a variety of actors from the private and civil society sectors (both local and otherwise). Inputs were thus assembled through a combination of in-kind contributions, partnerships, and the city's modest budget. Second, the use of low-cost technologies at the transport (i.e., WLAN) and terminal (i.e., open-source software) layers dramatically reduced upfront costs, allowing Piraí to provide broadband services where traditional cable and xDSL operators could not justify investments. ${ }^{15}$ Finally, local leadership, good governance and strong social capital enabled collective planning and management of the project, contributing to better match services with local needs.

The case for municipal networks is stronger when the local government is already providing other public services (e.g., electricity and sanitation), since economies of scope often allow provision of ICT services at minimal extra costs. A good example is the SICOMU (Sistema de Comunicaciones Multimediales) initiative in the Argentine province of La Pampa. This case illustrates the combination of market failures, economies of scope, and internal needs that often drive the municipal microtelco model. The project began as an appendix to the construction of a large aqueduct undertaken by the provincial government. Having contracted for over 1,300 kilometers of aqueduct building and secured the necessary rights of ways, provincial authorities decided to lay telecom fiber alongside the aqueduct.

The network was initially conceived as an Intranet that would support the internal control systems for the operation of the aqueduct. However it soon became evi-

\footnotetext{
${ }^{15}$ According to estimates by Franklin Dias Coelho, general project coordinator of Piraí Digital, the city was able to reduce deployment and operation costs by a factor of eight (personal interview).
} 
dent that excess capacity could be utilized to service municipalities along the aqueduct route with minimal incremental investments in feeder lines. The provincial government thus enlisted 21 municipalities to participate in the project, most of them rural communities with few other connectivity alternatives. While the provincial government operates the network backbone (the fiber along the aqueduct and feeder lines), each of the municipalities is responsible for extending the network to local government offices, hospitals, schools and public libraries, as well as selecting and managing the services provided at the local level (which range from e-government applications to IP telephony).

Other local actors also provide important complementary assets. The local university (Universidad Nacional de La Pampa) is utilizing the network for a variety of distance education initiatives (the university's only campus is located in the provincial capital of Santa Rosa). The local branch of the National Institute for Agricultural Technology (INTA) has made available online consultation and support services to local farmers. In addition, about half of the total network capacity is being offered as dark fiber to third parties for the commercialization of services in all or parts of the network. This is expected to offset a substantial part of the operating costs of the project. Local electricity cooperatives have already contracted to begin offering telephony services.

Whereas the public utilities of the past financed, built, and operated the entire network, municipal ICT projects today are more likely characterized by different degrees of cooperation with the private sector, CBOs, and other organizations (oftentimes educational institutions). Our findings indicate that municipal network projects aim at facilitating investments in underserved areas rather than competing with established operators. They also suggest how, as one of the largest users of ICT services in the community, local governments benefit from financing and/or managing their own infrastructure where private operators fail to invest adequately. Many municipal networks have emerged from the need to equip local government offices and public entities (schools, libraries, police stations, health centers, etc.) with better ICT access, later evolving into broader initiatives that service local businesses and residents. While further research is needed, preliminary findings suggest that both municipal and provincial authorities have an array of roles to play in spurring ICT development at the local level. 


\subsection{SMALL PRIVATE OPERATORS IN COLOMBIA}

While Colombia is among the few nations in the regions that have not fully privatized its legacy operators, the liberalization of the telecommunications market in 1994 has resulted in significant private investments in the sector. A large part of these investments has flowed into mobile telephony as well as into the legacy municipal operators, which have been privatized to varying degrees (Telecom, the national operator, remains public). ${ }^{16}$ Yet market reforms have also resulted in the emergence of a number of small private operators, many of them serving areas poorly served by the incumbents. While some of these operators are affiliates of larger firms with presence in various local markets, others are the product of independent efforts by small entrepreneurs who bear the majority of the risks themselves.

The evidence suggests that small-scale private operators are gaining ground in the Colombian market. As the total number of fixed lines roughly doubled between 1994 and 2002, the number of lines controlled by small operators more than tripled in the same period, increasing their share from $7 \%$ in 1994 to $11 \%$ in $2002 .{ }^{17}$ The available data also reveals that small-scale operators compare favorably with larger firms on standard quality measures. The Quality Index computed by the Colombian regulator (which is factored into price regulations) reveals that small operators consistently outperform larger operators as measured by traditional quality indicators (faults per 100 lines, average days to obtain new connection, average days to repair a faulty line) as well as subscriber satisfaction surveys. ${ }^{18}$

Small private operators nonetheless still face a myriad of challenges, even when serving areas neglected by incumbents, which the case of TELEOCSA illustrates well. The birth of TELEOCSA dates back to the early 1990s when a group of community leaders from Puente Piedra, a small town near the capital city of Bogotá, approached the national operator (Telecom) to request the extension of local telephony services to the community. Lacking the capital and the incentives to fulfill the request, Telecom instead proposed to community leaders that local residents purchase the equipment (including switches and cabling), deploy the network, and later transfer ownership of all facilities to Telecom, which would then operate the network and provide interconnection with its long-distance lines.

Lacking alternatives, community leaders agreed to these terms and the project

\footnotetext{
${ }^{16}$ For further details see Uribe Botero (2005).

${ }^{17}$ Source: CRT.

${ }^{18}$ In 2001 for example, the average Quality Index score (on a 100-point scale) for small operators was 90.1 , compared to 89.4 for medium-size operators and 87 for large operators. Source: authors' own calculations based on CRT (2002).
} 
was started soon after. With the passing of the new telecommunications law in 1994 that allowed unrestricted private sector participation in the provision of local telephony, community leaders changed course and decided to create a private local operator rather than transfer ownership to Telecom. A year later, TELEOCSA was incorporated and obtained a local operator license. What ensued was a protracted regulatory battle between the new company and the incumbent, which not only refused to interconnect but asserted ownership over TELEOCSA's facilities, even when the totality of the investment was borne by local residents. At its peak in 2002 TELEOCSA had 1,200 subscribers, but after several unsuccessful attempts to obtain interconnection with Telecom's long-distance network the project was folded in November 2004.

This case illustrates the need for a vigilant regulator to protect new entrants from anti-competitive strategies by the incumbents in control of higher-level facilities. While this is the case for any new entrant, it is particularly important for the emergence and survival of microtelcos, which cannot bargain effectively with incumbents and typically lack the resources or expertise to wage lengthy regulatory or judicial battles. The next section discusses this and other regulatory obstacles faced by microtelcos.

\section{The Need for an Enabling Regulatory Environment}

Regulatory constraints have long been a major barrier to entry in the ICT markets of Latin America and the Caribbean. Despite ongoing reforms, our findings indicate that microtelcos face a myriad of regulatory barriers that discourage entry, limit scalability and constrain experimentation with new technologies and business models better suited to service high-costs/low-income areas.

Spectrum access. Our case studies suggest that Wi-Fi and other WLAN technologies represent key enabling technologies for microtelcos, having been deployed to provide a variety of services (from broadband Internet access to VoIP) in different social and geographic contexts. This is however premised on the availability of the frequency bands in which these technologies operate $(2.4 \mathrm{GHz}$ and $5 \mathrm{GHz})$. International experience reveals that spectrum policies that provide for unlicensed access to these bands empower microtelcos by facilitating rapid infrastructure deployment without the lengthy administrative procedures traditionally associated with wireless networks (Galperin and Bar, 2004).

In recent years, countries in the Latin America and Caribbean region have been reforming spectrum administration to allow for increased unlicensed use by lowpower devices (such as Wi-Fi radios) in these bands. However, our findings from a 
survey of 25 countries in the region reveal that significant roadblocks persist. ${ }^{19}$ The vast majority (82\%) of the countries in the region have taken steps to allow for unlicensed WLAN deployment in the $2.4 \mathrm{GHz}$ band, though about a third of them still require public access points to be registered with the telecom authority. While this is encouraging, in many countries power restrictions significantly limit outdoors deployment opportunities (and thus the appeal of the technology for new service providers). Overall, a third of the countries have set power limits below $1 \mathrm{~W}$ (the FCC standard), thus limiting the potential reach of Wi-Fi signals to a few hundred meters at best (although in certain cases such as Brazil and Peru exceptions are made for the less populated areas). ${ }^{20}$

In the $5 \mathrm{GHz}$ band, the situation is less encouraging. About two-thirds of the countries $(68 \%)$ allow unlicensed operation in the upper portion of the band (5.725$5.850 \mathrm{MHz}$ ), and of those $40 \%$ require equipment registration with the telecom authorities. Moreover, of the countries where unlicensed use is authorized, $40 \%$ of them restrict power below $1 \mathrm{~W}$ (the FCC standard). ${ }^{21}$ In the lower portion of the band $(5.150-5.350 \mathrm{MHz})$, only about a third (35\%) of the countries in the region authorize unlicensed use in these frequencies, and in most of these cases operation is limited to indoor spaces. ${ }^{22}$ Finally, only Brazil, Panama and Colombia have so far authorized unlicensed use in the middle portion of the $5 \mathrm{GHz}$ band $(5.470-5.725 \mathrm{MHz})$. Although this is expected to change in the medium term as these frequencies have only recently been designated by the ITU for WLAN devices, there are less encouraging cases such as Mexico where telecom authorities have recently designated the band for licensed use exclusively.

Licensing. Licensing rules often discriminate against microtelcos, either implicitly by requiring lengthy administrative procedures that microtelcos are unable to navigate, or explicitly by preventing non-traditional operators from controlling network components or supplying services. As an example, telephone cooperatives in Argentina are legally barred from offering broadcasting and other complementary services, thus preventing bundling strategies. In Peru, the Chancay-Huaral project discussed above was prevented from terminating voice calls in the PSTN because of

\footnotetext{
${ }_{19}$ The database is available from the authors upon request. It will also be available through www.wilac.net.

${ }^{20}$ In Brazil for example, the power limit is set at $400 \mathrm{~mW}$ for areas with more than 500,000 inhabitants, raising to $1 \mathrm{~W}$ for areas below 500,000.

${ }^{21}$ These power restrictions represent an even more serious constraint for service providers because of the propagation characteristics of radio signals at $5 \mathrm{GHz}$.

${ }^{22}$ While indoor-only use is the international norm in the $5.150-5.250 \mathrm{MHz}$ portion of the lower $5 \mathrm{GHz}$ band, many countries allow for outdoor use in the $5.250-5.350 \mathrm{MHz}$ range.
} 
the lack of a telecom operator license (obtaining such a license entails a lengthy administrative procedure which also triggers a number of financial obligations, including a contribution of $1 \%$ of operating revenues to the Peruvian telecommunications development fund). It is nonetheless encouraging that many nations are moving towards a differentiated licensing regime with less burdensome requirements for rural and underserved areas (this is the case of Peru and Argentina, among others).

Lack of technological neutrality. In the name of consumer protection, ICT services are sometimes subject to overly strict quality of service and engineering standards that preclude microtelcos from deploying low-cost solutions. This discourages seeking price/quality combinations better suited for the poor, and reduces opportunities for bypassing essential facilities controlled by incumbents. The case of VoIP is illustrative. Our survey of 18 countries in the region found that less than half of them (38\%) have authorized the use of IP networks to provide telephony services. Interestingly, only a handful explicitly prohibit the use of VoIP: in most cases, the technology is in a legal limbo, neither completely legal nor illegal.

This has not prevented many local entrepreneurs from offering VoIP services. In most countries in the region, telecenter operators offer long-distance calls over broadband connections at a fraction of the cost of incumbent carriers. Analysts estimate that Latin America accounts for 35\% of global VoIP traffic (compared to 9\% of PSTN). ${ }^{23}$ Yet lack of legal protection has discouraged further investments, and reports of government crackdowns on establishments and firms offering VoIP services on the grey market are not uncommon.

Another illustrative case are the service restrictions placed on the use of WLAN technologies. As discussed, in several cases the use of WLAN technologies is restricted to indoor spaces or private use, thus reducing the value of WLAN solutions as a last-mile access alternative for microtelcos. This was the case, until recently, of the 2.4GHz band in Peru, which required the Water Users Board in Chancay-Huaral to seek a special waiver from OSIPTEL (the Peruvian regulator) to deploy its network (the rules have since then been modified to allow outdoors deployment in underserved areas). There are also cases in which specific services are prohibited, such as in Argentina where regulators have recently prohibited the supply of telephony services over WLANs in the major metropolitan areas. As innovations continue to enhance the reach and capacity of wireless solutions, incumbents will attempt to seek protection against disruptive technologies, which will require increased regulatory vigilance to accepted principles of technological neutrality.

${ }^{23}$ Source: Telegeography (2004). 
Lack of financing. For traditional carriers servicing poor or distant communities, subsidy payments are often available through universal service and telecom development funds. In some cases, the administration of these funds discriminates against microtelcos by aggregating targeted areas and centralizing project management functions. The unintended result is that only large operators with a regional or national presence are able to compete for funds. This was for example the case of the Compartel program in Colombia, where in 1999 a large contract for the development of community telecenters was split between Gilat (670 telecenters) and Telefónica (270 telecenters). While this reduces administrative costs, it also jeopardizes long-term sustainability since services are dependent on the availability of external subsidies and unresponsive to local needs. Centralized projects are also more vulnerable to political patronage, as was the case with the failed CTC initiative in Argentina (Galperin, 2005).

Access to essential facilities. The provision of telecommunications services at the local level requires access to switching facilities and trunk lines often controlled by incumbent operators. Like many other new entrants, microtelcos often face discriminatory access to these facilities. While Latin American regulators are increasingly engaged in the oversight of interconnection contracts between incumbents and new entrants, their limited resources pose challenges to effective implementation. For example, a recent study found that few nations in the region provide guidance to the pricing and interconnection arrangements between incumbents and new entrants in the provision of broadband Internet access services (Regulatel, 2005). Lack of regulatory attention to issues of non-discriminatory access to essential facilities discourages entry by increasing the risks associated with last-mile infrastructure deployment. This is well illustrated in the case of TELEOCSA. 


\section{Conclusions}

Market reforms in the ICT sector in Latin America and the Caribbean have not paid sufficient attention to the important role that microtelcos play in the supply of services in thin markets outside the main urban centers. These operators have been found to provide services comparable to those of traditional operators in highcost/low-income areas with minimal public subsidies. They do so through a variety of innovative business and co-production strategies, combining inputs from local entrepreneurs, municipal authorities, and CBOs to address ICT needs in markets considered unprofitable by traditional operators.

One of the main advantages of microtelcos is their ability to adopt the technologies and business models best suited to serve local residents at different price/quality points. A variety of local conditions determine the optimal organization and combination of inputs for microtelcos, including the economic and social profile of the community, geographic factors (terrain, distance to urban centers, etc.) and the structure of the overall telecom market. However, our findings reveal that institutional factors are also critical. When good local governance exists (as in the Piraí case), municipal networks offer a promising alternative for spurring network rollout. When strong CBOs are present (as in the Chancay-Huaral case), microtelco projects may benefit from building upon their integration into the economic and social fabric of the community. In many cases local resources and entrepreneurship can be effectively activated (as in the TELEOCSA case), but this requires active regulatory support to prevent anti-competitive maneuvering by the incumbents.

Overall, our findings suggest that a level playing field for microtelcos is lacking. There is however encouraging evidence that the regulatory mood is changing. Principles such as technological neutrality, open access to essential facilities, and a public good rationale in certain ICT network components are beginning to take hold. Several nations have loosened licensing, spectrum access and tariff regulations to stimulate telecom investments in rural areas. There is also increasing recognition among policymakers that, alongside with private operators, public-private-CBO partnerships have an important role to play in extending networks and services to the rural poor. Finally, universal access programs in many nations now provide support for microtelco projects alongside large-scale subsidy schemes. Our findings provide support for these second generation reforms that acknowledge the diversification of ICT supply and community development spillovers as important principles in the design and implementation of ICT policies in the region. 


\section{References}

Azfar, O., \& Cadwell, C. (Eds.). (2003). Market-augmenting Government: The Institutional Foundations for Prosperity. Ann Arbor: University of Michigan Press.

Bar, F., \& Galperin, H. (2004). Building the Wireless Internet Infrastructure: From cordless Ethernet archipelagos to wireless grids. Communications and Strategies, 54(2), 45-68.

Benkler, Y. (2002). Some Economics of Wireless Networks. Harvard Journal of Law and Technology, $16(1), 25-83$.

Best, M. (2003). The wireless Revolution and Universal Access. In Trends in Telecommunications Reform. Geneva: ITU.

Birchall, J. (2003). Poverty Reduction through Self-help: Rediscovering the cooperative advantage. Geneva: International Labour Organisation (ILO).

Calzada, J. \& Dávalos, A. (2005). Cooperatives in Bolivia: Customer ownership of the local loop. Telecommunications Policy, 29, 387-407.

Comisión de Regulación de Telecomunicaciones. (2002). El sector de las telecomunicaciones en Colombia. Bogota: CRT.

Dongier, P., Van Domelen, J., Ostrom, E., Ryan, A., Wakeman, W., Bebbington, A., Alkire, S., Esmail, T., \& Polski, M. (2003). Community-driven Development. In World Bank Poverty Reduction Strategy Paper. Washington, DC: The World Bank.

Estache, A., Manacorda, M., \& Valletti, T. (2002). Telecommunications Reforms, Access Regulation, and Internet Adoption in Latin America. Economica, 2, 153-217.

Federal Communications Commission. (2005). Wireless Broadband Access Task Force report. Washington, DC: FCC.

Finquelievich, S., \& Kisilevsky, G. (2005). Community Democratization of Telecommunications Community Cooperatives in Argentina: The case of TELPIN. The Journal of Community Informatics, 1(3), 27-40.

Fischer, C. (1992). America Calling: A social history of the telephone to 1940. Berkeley: University of California Press.

Foster, V., \& Irusta, O. (2003). Does Infrastructure Reform Work for the Poor? A case study on the cities of La Paz and El Alto in Bolivia. World Bank Policy Research Working Paper No. 3177. Washington, DC: The World Bank.

Galperin, H. (2005). Wireless Networks and Rural Development: Opportunities for Latin America. Information Technologies and International Development, 2(3), 47-56.

Gerrard, C. (2000). Ten Institutionalist Perspectives on Agricultural and Rural Development. Presented at the IAAE Conference, Berlin.

Graham, T. \& Ure, J. (2005). IP Telephony and Voice over Broadband. Info, 7(4), 8-20.

Jhunjhunwala, A. (2000). Unleashing Telecom and Internet in India. Presented at the India Telecom Conference, Stanford University.

Noll, R. (2000). Telecommunications Reform in Developing Countries. In A.O. Krueger (Ed.), Economic Policy Reform: The Second Stage. Chicago: University of Chicago Press.

Ó Siochrú, S. and Girard B. (2005). Community-based Networks and Innovative Technologies: New models to serve and empower the poor. New York: UNDP

Ostrom, E. (1996). Crossing the Great Divide: Co-production, synergy, and development. World Development, 24(6), 1073-1087.

Regulatel. (2005). La Banda Ancha en el Ámbito de Regulatel. Mimeo. 
Saravia, M. (2005) Rural Telecommunications Networks in Peru. In Community-based Networks and Innovative Technologies, Ó Siochrú and Girard. New York: UNDP.

Uribe Botero, E. (2005). Evolución del Servicio de Telecomunicaciones Durante la Última Década. Documento CEDE 2005-23. Bogota: Universidad de los Andes.

Wallsten, S. \& Clarke, G. (2002). Universal(ly bad) Service: Providing infrastructure services to rural and poor urban consumers. Policy Research Working Paper Series 2868. Washington, DC: The World Bank.

Watson, G. (1995). Good SewersCcheap? UNDP/World Bank Water \& Sanitation Program. Washington, DC: The World Bank.

Wellenius, B. (2001). Closing the Gap in Access to Rural Communication: Chile 1995-2002. Washington, DC: The World Bank. 
